Voicing job satisfaction through Twitter

\title{
Voicing job satisfaction and dissatisfaction through Twitter: \\ Employees' use of cyberspace
}

\section{To Cite:}

Conway, E., Rosati, P., Monks, K., \& Lynn, T., Voicing job satisfaction and dissatisfaction through Twitter. New Technology, Work and Employment, 34(2): 139-156. 


\begin{abstract}
This article adopts a work orientations perspective to consider how, through the medium of Twitter, employees voice the things they love and hate about their jobs. Using 817,235 tweets posted by 650,958 users in the calendar year 2014 , the findings provide new insights into both the employee voice and job satisfaction/dissatisfaction literatures as well as an enhanced understanding of the nature of the employment relationship. First, our findings indicate that Twitter, in its expression of very personal and individualistic needs, might be considered a new form of employee voice. Second, Twitter captures the positive, the negative and the ambivalence in the notion of job satisfaction. Third, the description of the methodology used to access and analyse Twitter data illustrates how new methodological approaches, particularly those embedded within computer science, may be of value to social scientists in their analysis of 'Big Data'.
\end{abstract}

\title{
Keywords
}

Big Data; Employee voice; job dissatisfaction; job satisfaction; social media; Twitter; work orientations.

While there are extensive literatures on employee voice and job satisfaction, theories are generally located within clearly defined organisational structures and processes. But the advent of social media has changed dramatically the 
permeability of such structures. Employees, through mechanisms such as Facebook, Twitter or Instagram, now have both the opportunity and the means to voice their satisfaction and dissatisfaction with their jobs, and to a much wider audience than might ever have been envisaged by employers. Such developments have implications for the understanding of voice, job satisfaction/dissatisfaction and the employment relationship.

This article explores employees' use of Twitter as a channel to voice their positive and negative feelings about their jobs. A work orientations perspective (Bennett, 1974; Doorewaard et al., 2004; Goldthorpe et al., 1968; Warr and Inceoglu, 2018) is utilised to explore how, in a short ${ }^{1}$ tweet, employees express the things they love and hate about their jobs. There is a focus on 'hate' as well as 'love' since 'focusing exclusively on the positive ... represents a one-eyed view of the social world' (Fineman, 2006: 275). This use of Twitter is discussed against the backdrop of the employment relationship. In addition, the methodology used to access and analyse Twitter data draws on the tools and techniques of computer science and may therefore be of value to social scientists in their analysis of 'Big Data', as such data has widespread ramifications for research within these domains (Tinati et al., 2014).

The article begins by examining how voice, job satisfaction/ dissatisfaction and the employment relationship are understood within the extant literature and how the advent of social media suggests limitations to this understanding. The methodological approach used is then explained before the findings and their

\footnotetext{
${ }^{1}$ Twitter had a 140-character limit during the period covered by this study. Though the number of characters was increased to 280 in November 2017, it still remains very low compared with other social media platforms.
} 
implications are considered. The analysis shows that employees tweet about issues that have long been considered core to the employment relationship: the type of work that they do, the types of managers they have, and their relationships with their co-workers and customers. However, their sentiments are often expressed in powerfully emotive terms that are far removed from the anodyne language that has traditionally been employed by researchers to capture employee perceptions of satisfaction or dissatisfaction in large-scale quantitative research. These revelations provide insights into the types of issues that are at the core of contemporary work and the messages that employees may wish to send - to their managers, their organisations, their colleagues and very many unknown recipients - of their work experiences. As such, the findings contribute to the call for research that explores 'the phenomenon of employees' colonisation of cyberspace' and considers 'how such processes may well shed light on a wider range of issues in unpredictable work environments and the ever more precarious nature of employment' (Richards and Kosmala, 2013:76).

\section{Twitter and employee voice}

Twitter is an online form of microblogging that was developed in 2006 to enable individuals to post short 140 character messages (tweets) to others (Marwick and Boyd, 2010). Twitter has grown exponentially and includes content options such as photos, video and web-links. Twitter is a predominantly public forum which means that employees' tweets are accessible to a very wide audience beyond their own personal networks through 'retweeting', replying, and adding hashtags. Such 
mechanisms allow for the introduction and amplification of messages to a wider audience beyond those following the transmitting user. It has been argued that self-presentation is an important aspect of Twitter (Murthy, 2012) and that the often banal content is an 'important vehicle of self-affirmation' by providing 'ways for individuals to assert and construct the self which are contingent on a larger community of discourse' (Murthy, 2018, 32-33). Indeed, Twitter has been described as a 'microphone for the masses' (Murthy, 2011) and, as such, represents 'a demotic turn' (Turner, 2010, p. 2) where ordinary people can voice their views publicly. Employees, through Twitter, have both the opportunity and the means to voice about events in their jobs, no matter how significant or insignificant those events might be when viewed by others. At the same time, Twitter users may not necessarily represent the general population as one study found that they 'significantly over-represent the densely populated regions of the US, are predominantly male, and represent a highly non-random sample of the overall race/ethnicity distribution' (Mislove et al., 2011). Another study undertaken in the UK (Sloan, Morgan, Burnap and Williams, 2015) found that Twitter users tend to be younger than the general UK population, with $67.5 \%$ of users aged between 16 and 22 years.

Notwithstanding the advent of social media, theories of employee voice remain organisationally oriented: In the case of human resource management (HRM) and employee relations (ER) research, the focus is on formal voice mechanisms and the structures used to manage employee participation. Voice is regarded as a 
collective phenomenon with the potential to challenge management (Wilkinson and Fay, 2011). Mowbray et al. (2015: 15) contrast the HRM/ER perspective with that of the organisational behaviour (OB) discipline which concentrates more on informal voice, viewing it as 'discretionary, pro-social behaviour, with the primary motive being to improve unit or organizational functioning' (Morrison, 2011; Van Dyne and LePine 1998). Even more so than HRM/ER, the OB discipline has confined its understanding of employee voice to within the organisation, and has narrowed the concept to focus on extra-role or organizational citizenship behaviours (OCB), with the organisation rather than the employee as beneficiary (Morrison, 2014). Morrison (2014) proposes that it is useful to distinguish between suggestion-focused voice, problem-focused voice and opinion-focused voice. Suggestion-focused voice is the communication of suggestions or ideas about how to improve the work unit or organization; problem-focused voice relates to an employee's expression of concern about work practices, behaviours or ideas that s/he regards as harmful or potentially harmful to the organization; while opinionfocused voice is about communicating views on work-related issues that differ from those held by others. However, none of these mechanisms leave room for employees to express their dissatisfaction with aspects of their working. The advent of social media has therefore changed dramatically the perviousness of organisational structures. It is not only the case that new channels for voice - which may or may not be sanctioned by the organisation - have emerged, but the way in which voice might be expressed has also changed. As Balnave et al. (2014) point out, users of social media can upload video, photo and text almost instantly with 
the potential to disseminate this material to a wide audience that is geographically disperse with 'ramifications for collective as well as individual expressions of voice' (p. 440). Yet, while it is acknowledged that employee voice mechanisms are evolving and that the targets of voice are broadening as they respond to macrolevel changes such as the use of social media (Mowbray et al., 2015), very little research has been undertaken to explore how this is taking place and what the implications are for the conceptualisation of employee voice. This leads to research question one: in the context of job satisfaction/dissatisfaction, what is the nature of employee voice when Twitter is the communication mechanism?

\section{Employee voice and job satisfaction}

The multi-faceted nature of job satisfaction, as well as the fact that it holds different meanings for researchers from different disciplines, creates levels of complexity in interpreting what workers mean when they pronounce themselves to be satisfied or dissatisfied with their jobs. The literature on job satisfaction is extensive. Two main streams of research - one from psychology and one from sociology - provide a variety of insights. A recent review from a psychological perspective (Judge, Weiss, Kammeyer-Muller and Hulin, 2017) describes how the construct has developed over time and yet notes that gaps in understanding still remain. They trace the early research by Herzberg, Mausner and Snyderman (1959) which focused on notions of satisfiers and dissatisfiers in work to more recent work which builds on this notion in its consideration of attitudinal conflict in which positive and 
negative evaluations of a job may coexist, thereby leading to ambivalence (van Harreveld, Nohlen and Schneider, 2015). Judge et al. (2017: 366) provide examples such as 'the consequences for a worker who holds a job that produces positive attitudes because of the positive humanist features like meaning and interesting work, but which also produces negative attitudes because it incorporates low pay and low social status'. Such notions of within and between object variance are not easily captured by standard job satisfaction Likert scales, which require individuals to place their attitudes in a bipolar attitude space. Judge et al. (2017) therefore propose that more grounded theory development is needed to better understand the independence of positive and negative attitude systems, where employees may describe negative features of their work for which there is no corresponding positive antipode.

From a sociological perspective, Brown, Charlwood and Spencer (2012: 1009) distinguish between the subjective approach to job satisfaction that focuses on well-being (Sousa-Poza and Sousa-Poza, 2000) with the objective approach to job quality, defined as 'overlapping job characteristics that satisfy work-related needs'. These include elements such as pay, the creative content of work, interest inherent in work, relationships with colleagues, position within the organization/class hierarchy, work influence, skill etc. Similarly, Rose (2003: 509) suggests that patterns in job satisfaction are the outcome of five different types of influence: the terms and conditions of the employment contract, working hours, monetary rewards, the work situation, and workers' orientations and career aims. The nature of work orientation has been explored in some detail by sociologists 
(Goldthorpe et al., 1968; Rose, 2003; Warr and Inceoglu, 2018). Rose (2003) also suggests that it is necessary to explore both the extrinsic or instrumental aspects of employment, such as promotion, pay or job security as well as the intrinsic quality of work such as relationships with managers and the nature of work itself. A framework has also been proffered (Doorewaard et al., 2004) that integrates work orientations with work motivation. This framework distinguishes beween three categories of work orientation: a 'job' orientation, a 'people' orientation and a 'money' orientation (Doorewaard et al., 2004: 9) and includes an indicator of whether these orientations reflect intrinsic (i.e. the nature of the work, relations with managers) or extrinsic (i.e. pay, promotion, hours of work) motives (Dooreward et al., 2004; Herzberg, Masuner and Snyderman, 1959; Rose, 2003).

Social scientists have traditionally employed either quantitative techniques, such as surveys, or qualitative techniques, such as interviews, to garner insights into employees' work views. Surveys usually confine responses to carefully constructed and predefined questions on specific elements of work and may not necessarily always capture what it is that employees may wish to voice about their satisfaction or dissatisfaction with their jobs. While rich insights are captured from qualitative studies (e.g. Gold and Mustafa, 2013; Sayers and Fachira, 2015), these generally access only small numbers of employees. However, in both cases, responses are, to a greater or lesser extent, mediated by the presence of the researcher. In contrast, Twitter offers 'an unmediated glimpse into the world of work' (Schoneboom, 2011a: 133). At present there is limited research exploring how Twitter may be used to voice job satisfaction/dissatisfaction. An analysis of 
38,124 tweets of 433 employees in professional jobs (van Zoonen et al., 2016) found that approximately a third of these were work-related and that these referred most frequently to the profession, the organisation, work behaviours and in-group communication. The research by van Zoonen et al. bundled the ways in which employees communicated their views using the theme of 'sentiment', broken down into personal positive, neutral or negative feelings, emotions or opinions and found that the majority of employees' tweets were characterised by a neutral sentiment. In the light of these insights, research question two asks: does the advent of Twitter challenge extant theories of job satisfaction?

\section{Employee voice, job satisfaction and the employment relationship}

A recent analysis of the impact of social media on the employment relationship suggests that social media technologies provide a 'shared space for discontinuous and asymmetric concerns from employment relations actors' (McDonald and Thompson, 2016, p. 75). Boundaries between work and non-work and between public and private lives have blurred, thus opening up new possibilities for contestation in the employment relationship (Hurrell, Richards and Scholarios, 2013; McDonald and Thompson, 2016; Rose, 2003). From an employee's perspective, voice opportunities available through social media, such as Twitter, might be viewed as 'a rationale for communicating work experiences considered authentic to those outside the organisation'. At the same time, how these experiences are framed is of interest to employers who are interested in 'protecting and promoting a positive brand image to relevant stakeholders' (McDonald and 
Thompson, 2016: 80). This might explain why employers are increasing their surveillance of employees through their monitoring of employees' - or potential employees' - use of social media (Richards, 2008; Chory, Vela and Avtgis, 2016) and such monitoring has the potential to extend employer control into employees' non-work lives (Hurrell et al., 2013).

Evidence from the literature on blogging, of which Twitter is a variant, suggests that it is 'primarily about communication' and 'allows employees a novel mode of expression', indicating that 'whether employees are happy with their work or not, employees seem far from satisfied with current arrangements (whether provided by the organisation or not) for discussing and debating their jobs and the challenges they face at work' (Richards, 2008, p. 106). Richards indicates that his findings point 'towards a shifting locus of conflict expression: from workspace to cyberspace' (p. 9) and that 'cyberspace can represent a new arena for selforganised conflict expression' (p. 10). Similarly, Schonenboom (2011b), in an analysis of an incident where a blogger was fired from Waterstones, identifies the blog as a vehicle for communicating dissent. It has been mooted (Richards and Kosmala, 2013: 76) that being cynical about work in their blogs may enable employees to 'resurrect and galvanise a sense of control and attachment to their own occupational or professional community, while providing distance from corporate culture initiatives'. Klaas et al. (2012: 337) also suggest that social media might be considered a form of justice-oriented voice where voice is used as revenge to harm the reputation of the employer. However, the limited evidence on this aspect of voice suggests that this might be very much an exception (Martin et 
al., 2012) and may depend on the influence that employees may have within their social networks.

Further linked to the potential to enhance or damage the reputation and brand of organisations is the potential 'reach' of employees' tweets. Evidence suggests that bad news and emotionally charged tweets tend to be shared more often and more quickly than good or neutral (i.e. informative) news (Hansen et al., 2011; Stieglitz and Dang-Xuan, 2013). While trustworthy and influential individuals have always played a key role in shaping other people's opinions and in building communities, the advent of social media has dramatically amplified their reach (Booth and Matic, 2011; Gillin, 2007). There is a growing, albeit much debated, literature on quantitative indicators of influence. This focuses on two inter-related themes - social media reach and social credibility. In early studies on social media, online popularity, captured by the number of "friends" one had on social networks, was often used as a predictor of social influence (Zywica and Danowski, 2008; Utz, 2010). However, as social networking has evolved the understanding of the nature of online popularity and influence has become more nuanced. Twitter, for example, has been characterised as a network of strangers (Lin and Qiu, 2013). Furthermore, an account's potential reach is not determined by merely the direct followers of that account but by all users who could access the tweets of a given account directly (by following) and indirectly through retweets, hashtags, search and other third-party interfaces on which Twitter is syndicated. Ohanian (1990: 41) defines source credibility as 'a communicator's positive characteristics that affect the receiver's acceptance of a message'. On social media, this may include self- 
generated information (e.g. tweets), other-generated information (e.g. followers' retweets and reply messages); and system-generated information (e.g. including the number of tweets, the number of followers, and the number of lists) (Jin and Phua, 2014). As such, online reach is a key predictor of source credibility. Other mechanisms such as whether an account is verified by the social networking site ("verified status") and third party social media "influence" rating systems, such as Klout, have been found to both increase the perceived trustworthiness (Abbasi and Liu, 2013; Chu et al., 2012) and general source credibility (Edwards et al., 2013) of a Twitter account. Organisations may therefore be more inclined to pay particular attention to what stakeholders with greater reach or perceived source credibility on social media, including employees, reveal on social media because of the potential effects on organisational reputations. This leads to research question three: what are the implications of the voicing of job satisfaction/dissatisfaction for the employment relationship?

\section{Methodology}

The study adopts a mixed methods approach, combining data science-based descriptive analytics and content analytics with manual coding. Both quantitative and qualitative data were used to examine specific user characteristics, namely trustworthiness and social reach, through the lenses of 'verified status' and Klout Scores. The research methodology can be divided into three main phases as summarised in Figure 1. 
Insert FIGURE 1 about here

Phase 1: Identify, extract and clean data

The data for the study was licensed and provisioned from DataSift, a commercial data aggregation platform that provides access to the entire Twitter firehose. The Datasift Historical Powertrack API platform was used as it allowed historical search and extraction from the Twitter corpus, provided additional augmented data, such as Klout scores, and avoided sampling issues reported by researchers using the limited public Twitter streaming API (Morstatter, Pfeffer, Liu and Carley, 2013). This API was queried for all English language tweets featuring the keywords 'love' and 'job' or 'hate' and 'job' that were posted over a 12-month period from January 1, 2014 to December 31,2014 . The JSON file containing the results of this query were downloaded and converted into a structured database. The initial dataset consisted of 2,121,139 tweets posted by 1,506,863 unique users comprising $1,926,108$ original tweets and 195,031 replies and 4,418 retweets. We limited the dataset to the following fields: timestamp, user screen name, summary (bio), verification status, Klout Score and message (tweet).

Once a base dataset was established, a manual inspection of a random sample of tweets revealed that the dataset contained a substantial number of tweets that were not work-related and therefore irrelevant to the study. In order to reduce the amount of 'noise', only those tweets meeting the following requirements were extracted from the initial dataset: (i) original tweets, as the study is only interested in what employees tweeted about rather than the conversation(s) they 
engaged in ( $n=195,031)$; (ii) tweets featuring the exact phrase 'love my job' or 'hate my job' and/or the hashtag "\#lovemyjob" or "\#hatemyjob", as these keywords/hashtags were clearly associated with work-related content; (iii) tweets expressing clear emotions. Our final dataset consists of 817,235 tweets posted by 650,958 users.

\section{Phase 2: Tweets and users classification and statistical analysis}

In order to extract information from the dataset, two automated classifiers were developed in R. First, an occupation classifier using a bag-of-words approach was developed to ascertain the types of individuals who were tweeting about their jobs. The initial list of keywords used to develop the classifier included the full list of occupations provided by the International Standard Classification of Occupations (ISCO, 2018). This initial list was then manually extended to include position acronyms (e.g. CEO, CTO etc.) or titles (e.g. Chief Executive Officer. Chief Technology Officer etc.). Pruning of the vocabulary was used to reduce the dimension of the document-term matrix and improve the effectiveness of the classification (Leskovec, Rajaraman, and Ullman, 2014; Madsen, Sigurdsson, Hansen and Larsen, 2004). Second, a topic classifier was developed to identify the work-related topic(s) mentioned in the tweets. Again, a bag-of-words approach based on pruning (Madsen et al., 2004) combined with a document-term matrix (Leskovec et al., 2014) was adopted but the initial list of keywords was identified through a more conventional manual coding. To complete this manual coding, two researchers working independently analysed a sample of 2,312 tweets and 
created categories based on the topic(s) mentioned in the tweet in order to identify associated keywords. Five themes were identified: working hours, working relationships (with manager, co-workers and customers), pay, working conditions, and the nature of the job. These themes resonated with those found in the extant literature on work orientations and so it was decided to adapt the work orientation scheme utilised by Doorewaard et al., (2004) as a mechanism for categorising the data. Following the manual coding, the list of keywords was then extended to include additional words that the same two researchers identified for each category within the most frequently occurring terms in each of the two high-level clusters of tweets (hate and love). This was performed using word frequency analysis using the 'tm' package in R (Feinerer, 2018) after removing standard stop words (e.g. 'and', 'to' etc.) in order to ensure that only meaningful words were actually counted. All tweets in the dataset were then automatically classified. Table 1 presents the coding scheme, starting with the keywords identified in the tweets, the categories which were used to capture these key words, the ways in which these categories were defined, and the orientation chosen to capture the specific elements.

Insert TABLE 1 about here

A series of statistical analyses was then performed in order to investigate the relationship between hate/love, work-related topic(s) and users' characteristics such as trustworthiness and social reach. 'Verified status' was used as a proxy for trustworthiness (Abbasi and Liu, 2013; Chu et al., 2012) and Klout Score was used as a proxy for social reach. While Klout has been critiqued due to its lack of 
transparency (Gandini, 2014), academic studies suggest that it is a useful proxy for data that is often difficult to source and can be a source of credibility in itself (Bode and Epstein, 2015; Edwards et al., 2013). A year-long study of 87,675 Klout users provides compelling data that users with higher Klout Scores are able to spread information more effectively in a network than those with lower Klout scores (Rao et al., 2015). In this study, we are interested in the implications of employee voice on Twitter and of social reach for the employment relationship. Based on Rao et al. (2015), Klout captures a wider set of features within Twitter and signals beyond Twitter to provide a rating of social reach. As such, in the absence of a more effective measure of social reach, Klout is used.

Descriptive statistics captured the frequency of tweets and users across the two high-level clusters of tweets (hate and love), different levels of users' social reach, and different topics. A logistic regression ${ }^{2}$ was also implemented in order to empirically test the contemporaneous effects of different user characteristics and specific job-related attributes on the probability of a user tweeting positively (i.e. love) or negatively (i.e. hate) about his/her job. Hate was categorised as a binary variable equal to 1 if a tweet contained the phrase 'hate my job' or the hashtag '\#hatemyjob', or 0 otherwise. Klout Scores, which range from zero to 100 , were classified based on terciles; users with a score of greater than 66.66 were classified as high, those with a score of 33.33 or less were scored as low, and those in between were classified as medium. The binary variable (Klout(Low)

\footnotetext{
${ }^{2}$ Regression coefficients were estimated using both standard maximum-likelihood and robust variance estimator in order to ensure that results were not affected by observations dependence (Le Cessie and Van Houwelingen, 1994). Results are consistent across different estimation procedures.
} 
$<=33.33$ ) was not included in the regression model to prevent potential multicollinearity and was therefore used as a baseline to interpret the effects of Klout(Medium) and Klout(High). Verified Status was coded 1 if a user had a verified account, or 0 otherwise. Other explanatory variables were coded 1 if a tweet mentioned any of the five factors presented in Table 1 and 0 otherwise.

\section{Phase 3: Results Validation}

The aim of the third phase was to validate the results of the statistical analysis, particularly in relation to users with higher reach (i.e. users with high Klout Scores). Two additional coders worked independently and manually classified a subset of 1,929 tweets posted by users with high Klout Scores in order to verify the validity of the automated classification (i.e. hate $v$. love, and job dis/satisfaction factors). The revised classification was then used within the same regression model presented above and findings were consistent.

\section{Results}

The findings are presented in two parts. The first part details findings from the manual and automated classification, while the second part provides the main findings from the logistic regression analysis.

\section{Manual and machine classification}

The occupation classification revealed that $20 \%$ of the sample $(127,155$ users) provided occupational details. Table 2 shows the breakdown of occupations with $16.30 \%$ identifying themselves as managers. The largest group was that of 
'professionals', which encompassed a very diverse range of occupations such as actors, dancers, artists, nurses and doctors. The breakdown of occupations is broadly similar to that found in a recent study using a UK classification system (Sloan et al., 2015), which noted the unusually high representation of creative occupations and which was also found in our sample. They suggest that Twitter is 'used by people who work in the creative industries as a promotional tool' (p.8). Again our data supports this suggestion as some of those describing themselves as actors and dancers in our sample included various media as part of their tweets.

Insert TABLE 2 about here

The initial manual inspection provided valuable insights into the wide range of work experiences about which individuals tweeted. For example, some individuals attached video or web links to their tweets. While some of these simply showed innocuous pictures of work situations, others led to explicit pornographic sites that provided a snapshot of the type of work undertaken by the presumed sex workers in the sample. Table 3 provides some sample 'love my job' and 'hate my job' tweets from the various categories identified.

Insert TABLE 3 about here

A number of tweets in the dataset $(n=31,215)$ did not contain a clear expression of love or hate. A sample of these tweets is presented in Table 4. Insert TABLE 4 about here 
These sample tweets show the extent to which 'love' or 'hate' for a job is to a large degree conditional. For example, tweets expressed love for the job, but at the same time signalled hate when, for example, working long hours or fighting fatigue, dealing with death or when dealing with rude bosses or customers. Tweets that mentioned overall dissatisfaction for the job also indicated love for certain aspects of it, such as for co-workers. These were removed for the main statistical analysis since they did not convey clear emotions and therefore could not be expressed as a binary variable (i.e. where $1=$ hate and $0=$ love).

\section{Statistical analysis}

Table 5 reports the total number of tweets and users by satisfaction category (i.e. Hate or Love), and by user social reach based on the Klout Score categories described above.

Insert TABLE 5 about here

The table shows that 658,763 tweets ( 80.6 per cent) were associated with job satisfaction (Love), while only 158,472 tweets (19.4 per cent) were associated with job dissatisfaction (Hate). The ratio between positive (i.e. Love) and negative (i.e. Hate) tweets is similar for medium and low Klout Score users. In the case of users with a high Klout Score, only 118 of the tweets (5.8 per cent) expressed job dissatisfaction. The average level of user activity is very low (1.26), with slightly higher levels of activity among the high and medium Klout Score users (1.35 and 
1.34 respectively). The findings therefore suggest that more influential users are more likely to be in the Love category, but it also suggests that Twitter users do not tweet frequently about loving or hating their jobs. Table 6 reports the means and standard deviations of all variables for the full sample across both Love and Hate categories.

\section{Insert TABLE 6 about here}

The table shows that less than one per cent of tweets in the dataset originated from verified users and these were mostly associated with job satisfaction. It also shows that the average Klout Score fell just inside the Medium Klout category, which is the most represented in the dataset. Among the different job-related topics included in the classification framework, working hours was the most mentioned work feature in the full sample, followed by pay and relationships with managers. Similar patterns are found in both the Hate and Love sub-samples suggesting that such factors are relevant in expressions of both job satisfaction and dissatisfaction. Finally, the nature of the work was mentioned more in the Love $($ mean $=0.032)$ than in the Hate dataset (Mean $=0.014)$.

Table 7 reports the results of the logistic regression. In this analysis, the Klout Score and verified status variables were included first in the model, followed by each of the work orientations in a second step.

Insert TABLE 7 about here 
The analysis shows that most of the results were significant, with the exception of working conditions $(p=>.05)$. It shows that users with Medium Klout Scores were more likely to express job dissatisfaction compared to users with Low Klout Scores. It also shows that users with High Klout Scores were less likely to express job dissatisfaction compared to those with Low Klout Scores. In addition, users with verified status were less likely to tweet expressions of job dissatisfaction. The results also show that, among different job features, Relationship with Boss is the only one that was positively and significantly related to job dissatisfaction. The results further show that users are less likely to tweet about the nature of their job (an intrinsic job orientation) when expressing job dissatisfaction. The other work orientations that were significantly and negatively associated with job dissatisfaction were those mentioning co-workers, followed by customers, working hours and pay.

\section{Discussion}

The first research question concerned the nature of employee voice when Twitter is the communication mechanism. The findings showed that the tweets were predominantly positive. This is perhaps surprising as some research on blogging has suggested that this mechanism provides employees with the opportunity to vent about the negative aspects of their jobs, to seek justice, or to distance themselves from corporate culture (Klaas et al., 2012; Richards, 2008; Richards and Kosmala, 2013). At the same time this finding is in line with research which shows that social media users are more likely to share content with a positive or 
neutral rather than negative sentiment (van Zoonen et al., 2016) and that negative online utterances tend to be deemed inappropriate and incongruent with selfviews, particularly if the content is related to their professional life (Cheney and Lee Ashcraft, 2007; Marwick and Boyd, 2010). The higher percentage of positive tweets among highly influential users would also support this view. This is consistent with the argument that self-presentation and self-affirmation are important aspects of Twitter (Murthy, 2012; 2018). Second, there was little evidence of the collectivism that has been associated with employee voice in the HRM/ER literature (e.g. Wilkinson and Fay, 2011). For example, there was very little retweeting or evidence of efforts to build a community interested in pursuing a particular work-related agenda; the voice identified in this study was primarily individualistic. There was also little evidence of the suggestion or opinion-focused use of voice to improve organisational functioning in the ways proposed by $\mathrm{OB}$ scholars (e.g. Morrison, 2011). While the negative tweets did focus on work problems such as working hours, the supervisor/manager and the work itself, these were focused on personal needs with little interest or concern for organisational improvement. This finding is in line with prior research that indicated a significant relationship between job dissatisfaction and the use of social media to voice concerns at work among Generation $Y$ (younger) employees, although not among older employees (Holland et al., 2016). In its expression of very personal and individualistic needs, Twitter might therefore be considered a new form of employee voice that focuses on individual agency but not necessarily in the political way that has been suggested in research on blogging (Schoonenboom, 
2011a; Richards and Kosmala, 2013). Thus, while the content of these tweets may be regarded as banal to the observer (Murthy, 2018), this may not be the case for those experiencing joys and tribulations in their jobs

The second question asked whether the advent of social media challenges extant theories of job satisfaction. In regard to the value of the frameworks that have been used to classify and understand job satisfaction (e.g. Doorewaard et al., 2004; Goldthorpe et al., 1968; Rose, 2003), the findings suggest that such mechanisms continue to be valuable and applicable. Indeed, the types of issues about which individuals tweeted are very similar to those found in Rose's (2003) analysis of a large-scale sample of employees. At the same time, some differences do exist. First, the data point attention to the existence of job dissatisfaction which is often lost in contemporary enthusiasm for the positive aspects of work (Fineman, 2006). Second, the language used to voice aspects of job satisfaction/ dissatisfaction through Twitter is very different to the anodyne and managerialist language that is often reported in quantitative studies of job satisfaction. Employees utilised extensive, elaborate and emphatic language with the use of words such as 'amazing', 'awesome', 'fun', 'best', and 'great' in their description of positive features of their work. Expletives were used to some extent in the positive tweets but to a far greater extent in the negative tweets. Where individuals elaborated on why they 'hate their job', they used negative language and a large number of expletives. Thus, through Twitter, employees are enabled to voice how they feel about their jobs and to use an impassioned language to express these feelings. A similar use of language emerges in many qualitative studies but, as 
Schoneboom (2011b) has pointed out, twitter provides an unmediated view of the nature of work with opinions and emotions expressed without any prompting from researchers to determine the parameters of employees' views. As Murthy (2018, p. 45) suggests, through Twitter 'we are exposed to a certain candour' and we are 'perhaps getting more truthful portrayals of some sides of people, which were previously kept in the private sphere'. Third, the fact that individuals reported on the nature of their jobs by using the terms 'hate' and 'love' suggests that the notion of positive and negative attitude systems that originated with Herzberg is still relevant. However, there were a large number of tweets where individuals did not simply state that they loved or hated their jobs but indicated that their love or hate was not absolute; they might love or hate their jobs overall but at the same time also love or hate a particular element of their job. This points to an ambivalence that has been identified as an important emerging area in job satisfaction research (van Harreveld et al., 2015) and also suggests that the mining of Twitter data can provide a valuable way of identifying the factors that drive distinctly positive or negative attitudes (Judge et al., 2017). In this way, Twitter might be viewed as a new channel through which workers may express satisfaction or dissatisfaction or ambivalence with aspects of their jobs, thus shedding new understanding on the experience of work.

The third research question asked about the implications of the voicing of job satisfaction/dissatisfaction for the employment relationship. One of the fears of employers is that their employees will use social media to vent publically about their jobs and that negative views will have a correspondingly negative impact on 
organisational reputation. The data suggests first of all that employees are more likely to tweet positively about their jobs in ways that are beneficial to employers in enhancing their reputations. The exploration of the Klout Score also showed that those who are likely to have greater social reach tend to tweet that they love rather than hate their job. When employees tweet negatively in regard to hating their jobs it appears to be more likely to be a one-off event rather than a concerted effort to challenge or paint a damaging picture of their employers. There was also no evidence of attempts by employees to network with others or form communities that could be described as displaying concerted resistance to employer activities. Thus, there was no evidence of contestation of the employment relationship that has been mooted as a potential impact of social media (McDonald and Thompson, 2016; Hurrell et al., 2013). However, while organisational reputations may remain fairly intact, it was evident that there exist many difficulties for employees in negotiating their daily work lives. Working hours are often at the whim of the employer with some individuals forced to work several jobs in order to put together a viable income; managers and bosses, from their positions of power, may make employees' working lives either reasonable or impossible; the work itself may be difficult and undertaken in distressing working conditions. The surfacing of these factors to a wider audience therefore challenges the boundaries of the employment relationship; while working conditions and management philosophies have traditionally been the remit solely of the organisation, through Twitter they are brought out to a wider audience and provide the potential for a shared experience of working life. 


\section{Limitations}

While this study is in many respects ground-breaking, it has a number of limitations. First, at the time the study took place, tweets comprised at most 140 characters whereas Twitter users can now post longer tweets (up to 280 characters), which will provide a more comprehensive database for future research. Second, the effect size found in the statistical analysis was small. This finding is not unusual in studies using big data and reflects the sheer size and complexity of these datasets, which makes it impossible to compare such effects with studies using alternative methodologies such as surveys (Matz, Gladstone and Stillwell, 2017). It can however be seen as providing researchers with opportunities to gain insights which would not otherwise have been available. Third, the data suggests that only a small percentage of the population investigated were active users, yet capturing accurately the broader population of Twitter users who actively or latently participate as listeners remain difficult due to the syndication of Twitter feeds. Thus, beyond us knowing the number of re-tweets and replies, the true extent of the reach of work-related tweets is largely indeterminable without substantial cost and technical effort. Fourth, the study's dataset was based on tweets in the English language only, which limits the generalizability of the findings. Fifth, while we were able to analyse some tweets by occupation in order to provide insights into the types of individuals who were using Twitter, only $20 \%$ of tweets provided occupational details. In addition, Twitter is much more likely to be used by younger people and by professionals (Sloan et 
al., 2015) and so the data may be more representative of this section of the workforce rather than more widely generalizable.

\section{Conclusions}

In its exploration of 'the phenomenon of employees' colonisation of cyberspace' (Richards and Kosmala, 2013:76), the research provided new insights into aspects of employee voice and job satisfaction/dissatisfaction that are core to understanding the nature of the employment relationship as perceived by employees in their use of Twitter. While there are complexities in dealing with 'Big Data', at the same time it provides exciting new opportunities for researchers interested in learning more about the nature and experience of work.

\section{References}

Abbasi, M. and H. Liu (2013), 'Measuring user credibility in social media', Proceedings of the $6^{\text {th }}$ Annual Conference on Social Computing, BehavioralCultural Modeling and Prediction, 441-448.

Balnave, N., A. Barnes, C. MacMillan and L. Thornthwaite (2014), 'E-voice: How network and media technologies are shaping employee voice', in A. Wilkinson, Donaghey, J., Dundon, T. and Freeman, R. (eds), The Handbook of Research on Employee Voice. Northampton, MA: Elgar, 439-454.

Bennett, R. (1974), 'Orientation to work and some implications for management', Journal of Management Studies, 11, 2, 149-162. 
Bode, L. and B. Epstein (2015), Campaign Klout: Measuring online influence during the 2012 election. Journal of Information Technology \& Politics, 12, 2, 133-148.

Booth, M. and J. Matic (2011), 'Mapping and leveraging influences in social media to shape corporate brand perceptions', Corporate Communications: An International Journal, 16, 3, 184-191.

Brown, A., A. Charlwood and D. Spencer (2012), 'Not all that it might seem: why job satisfaction is worth studying despite it being a poor summary measure of job quality', Work, Employment and Society, 26, 6, 1007-1018.

Cheney, G. and K. Lee Ashcraft (2007), "Considering "the professional" in communication studies: Implications for theory and research within and beyond the boundaries of organisational communication', Communication Theory, 17, 2, 146-175.

Chory, R., L. Vela and T. Avtgis (2016), 'Organizational surveillance of computermediated workplace communication: Employee privacy concerns and responses', Employee Responsibilities and Rights Journal, 28,1, 23-49.

Chu, Z., S. Gianvecchio, H. Wang and S. Jajodia (2012), 'Detecting automation of twitter accounts: Are you a human, bot, or cyborg?' IEEE Transactions on Dependable and Secure Computing, 9, 6, 811-824.

Doorewaard, H., J. Hendrickx and P. Verschuren (2004), 'Work orientations of female returners', Work Employment and Society, 18, 1, 95-115. 
Edwards, C., P. Spence, C. Gentile, A. Edwards and A. Edwards (2013), 'How much Klout do you have? A test of system generated clues on source credibility', Computers in Human Behavior, 13, A12-A16.

Feinerer, I. (2018), 'Introduction to the tm package text mining in R'.

https://cran.r-project.org/web/packages/tm/vignettes/tm.pdf (accessed 28 November 2018).

Fineman, M. (2006), 'On being positive: concerns and counterpoints', Academy of Management Review, 31, 2, 270-91.

Gandini, A. (2014), 'Online social influence and the evaluation of creative practice: A critique of klout', In Online Evaluation of Creativity and the Arts (pp. 162180). Routledge.

Gillin, P. (2007), The New Influencers. Sanger CA: Word Daner Press.

Gold, M. and M. Mustafa, (2013), 'Work always wins: Client colonization, time management and the anxieties of connected freelancers', New Technology Work and Employment, 28, 3, 197-211.

Goldthorpe, J., D. Lockwood, F. Bechhofer and J. Platt (1968), The Affluent Workers: Industrial Attitudes and Behaviour. Cambridge: Cambridge University Press.

Hansen, L.K, A. Arvidsson, F. Nielsen, E. Colleroni and M. Etter (2011), 'Good friends, bad news-affect and virality in Twitter', Proceedings of the 6th International FutureTech Conference, 2, 34-43.

Herzberg, F., B. Mausner and B. Snyderman (1959), The Motivation to Work, New York, Wiley. 
Holland, P., B. Cooper and R. Hecker (2016), 'Use of social media at work: a new form of employee voice?', The International Journal of Human Resource Management, 27, 21, 2621-2634.

Hurrell, S. A., J. Richards and D. Scholarios (2013), 'The kids are alert': Employed students' experiences of and attitudes towards the use of social networking sites in recruitment and employment', Paper presented at International Labour Process Conference, New Brunswick, NJ, United States.

International Standard Classification of Occupations (2018), Geneva: International Labour Organization.

Jin. S. and J. Phua (2014), 'Following celebrities' tweets about brands: The impact of Twitter-based electronic word-of-mouth on consumers' source credibility perception, buying intention, and social identification with celebrities', Journal of Advertising, 43, 2, 181-195.

Judge, T., H. Weiss, J. Kammeyer-Mueller and C. Hulin (2017), 'Job attitudes, job satisfaction and job affect: a century of continuity and change', Journal of Applied Psychology, 102, 3, 356-374.

Klaas, B., J. Olson-Buchanan and A.K. Ward (2012), 'The determinants of alternative forms of workplace voice: An integrative perspective', Journal of Management, 38, 1, 314-345.

Le Cessie, S. and J.C. Van Houwelingen (1994), 'Logistic regression for correlated binary data', Applied Statistics, 95-108.

Leskovec, J., A. Rajaraman, and J.D. Ullman (2014). Mining of Massive Datasets, New York, Cambridge University Press. 
Lin, H., and L. Qiu (2013), 'Two sites, two voices: Linguistic differences between Facebook status updates and Tweets', in: Rau, P.L.P. (ed.), Cross-Cultural Design: Cultural Differences in Everyday Life. Springer, Berlin Heidelberg, pp. 432-440.

Madsen, R. E., S. Sigurdsson, L.K. Hansen, and J. Larsen (2004), 'Pruning the vocabulary for better context recognition', Proceedings of the 17th International Conference on Pattern Recognition, 2, 483-488.

McDonald, P. and P. Thompson (2016), 'Social media(tion) and the reshaping of public/private boundaries in employment relations', International Journal of Management Reviews, 18, 60-84.

Martin, G., E. Parry and P. Flowers (2015), 'Do social media enhance constructive employee voice all of the time or just some of the time?', Human Resource Management Journal, 25, 4, 541-562.

Marwick, A. E. and D.M. Boyd (2011), 'I tweet honestly, I tweet passionately: Twitter users, context collapse, and the imagined audience', New Media \& Society, 13,1, $114-133$.

Matz, S.C., J.J. Gladstone, and D. Stillwell (2017), 'In a world of big data, small effects can still matter: A reply to Boyce, Daly, Hounkpatin, and Wood (2017)', Psychological Science, 28, 4, 547-550.

Mislove, A., D. Lehmann, Y-Y Ahn, J-P Onnuel, J. Niels Rosenquist (2011), 'Understanding the demographics of Twitter users', Proceedings of the Fifth International AAI Conference on weblogs and social media. 
Morrison, E. (2011), ‘Employee voice behaviour: Integration and directions for future research', The Academy of Management Annals, 5, 1, 373-412.

Morrison, E. (2014), 'Employee voice and silence', Annual Review of Organizational Psychology and Organizational Behavior, 1, 173-197.

Morstatter, F., J. Pfeffer, H. Liu and K.M. Carley (2013), 'Is the sample good enough? Comparing data from Twitter's Streaming API with Twitter's firehose', Proceedings of the seventh International AAAI Conference on Weblogs and Social Media, 400-408.

Mowbray P., A. Wilkinson and H. Tse (2015), 'An integrative review of employee voice: Identifying a common conceptualization and research agenda', International Journal of Management Reviews, 17, 382-400.

Murthy, D. (2011), 'Twitter: Microphone for the masses?', Media, Culture and Society, 33,5, 779-789.

Murthy, D. (2012), 'Towards a sociological understanding of social media: Theorising Twitter', Sociology, 46, 6, 1059-1073.

Murthy, D. (2018), Twitter. Cambridge: Policy Press.

Ohanian, R. (1990), 'Construction and validation of a scale to measure celebrity endorsers' perceived expertise, trustworthiness, and attractiveness', Journal of Advertising, 19,3, 39-52.

Rao, A., N. Spasojevic, Z. Li and T. Dsouza (2015), 'Klout Score: Measuring influence across multiple social networks', Proceedings of the IEEE International Conference on Big Data, Oct-Nov, 2282-2289. 
Richards, J. (2008), '"Because I need somewhere to vent": The expression of conflict through work blogs', New Technology, Work and Employment, 23(12), 95-110.

Richards, J. and K. Kosmala, (2013), 'In the end you can only slag people off for so long: employee cynicism through work blogging', New Technology, Work and Employment, 28, 1, 66-77.

Rose, M. (2003), 'Good deal, bad deal? Job satisfaction in occupations', Work, Employment and Society, 17, 3, 503-530.

Sayers, J. and I. Fachira (2015), 'Telling tales: on-line comic and gripe story-telling by service workers about difficult customers', New Technology Work and Employment, 30, 2, 128-144.

Schoneboom, A. (2011a), 'Workblogging in a Facebook age', Work, Employment and Society, 25, 1, 132-140.

Schoneboom, A. (2011b), 'Sleeping giants? Fired workbloggers and labour organisation', New Technology, Work and Employment, 26, 1, 17-28.

Sloan, L., J. Morgan, P. Burnap and M. Williams (2015), 'Who tweets? Deriving the demographic characteristics of age, occupation and social class from Twitter user meta-data'. PLoS ONE 10, 3, 1-20.

Sousa-Poza, A. and A. Sousa-Poza (2000), 'Well-being at work: A cross-national analysis of the levels and determinants of job satisfaction', Journal of SocioEconomics, 29, 517-538. 
Stieglitz, S. and L. Dang-Xuan (2013), 'Emotions and information diffusion in social media—sentiment of microblogs and sharing behavior', Journal of Management Information Systems, 29, 4, 217-248.

Tinati, R., S. Halford, L. Carr and C. Pope (2014), 'Big Data: Methodological challenges and approaches for sociological analysis', Sociology, 48, 4, 663681.

Turner, G. (2010), Ordinary People and the Media: The Demotic Turn. London: Sage.

Utz, S. (2010), 'Show me your friend and I will tell you what type of person you are: How one's profile, number of friends, and type of friends influence impression formation on social network site', Journal of Computer-Mediated Communication, 15, 2, 314-35.

Van Dyne, L. and J.A. LePine (1998), 'Helping and voice extra-role behaviours: evidence of construct and predictive validity', Academy of Management Journal, 41, 108-119.

van Harreveld, F., H. Nohlen, and I. Schneider (2015), 'The ABC of ambivalence: Affective, behavioral, and cognitive consequences of attitudinal conflict', Advances in Experimental Social Psychology, 52, 285-324.

van Zoonen, W., J. Verhoeven and R. Vliegenthart (2016), 'How employees use Twitter to talk about work: A typology of work-related tweets', Computers in Human Behavior, 55, 329-339. 
Warr, P. and I. Inceoglu (2018), 'Work orientations, well-being and job content of self-employed and employed professionals', Work Employment and Society, $32,2,292-311$.

Wilkinson, A. and C. Fay (2011), 'Guest Editors' Note: New times for employee voice', Human Resource Management, 50, 1, 65-74.

Zywica, J. and J. Danowski (2008), 'The faces of Facebookers: investigating social enhancement and social compensation hypotheses; predicting Facebook and offline popularity from sociability and self-esteem, and mapping the meanings of popularity with semantic networks', Journal of Computer-Mediated Communication, 14,1, 1-34. 
Table 1. Coding categories

\begin{tabular}{|c|c|c|c|}
\hline Sample Keywords & Category & Definition & Orientation \\
\hline $\begin{array}{l}\text { night; shift; day; flexible; time; } \\
\text { hours; part-time; overtime; } \\
\text { vacation; holiday; weekend. }\end{array}$ & Working Hours & $\begin{array}{l}\text { Reference to work schedules: Shift work; } \\
\text { split shifts; early mornings; overtime; part- } \\
\text { time work; erratic hours; zero hour } \\
\text { contracts; flexible work. }\end{array}$ & $\begin{array}{l}\text { Job- } \\
\text { oriented; } \\
\text { extrinsic }\end{array}$ \\
\hline $\begin{array}{l}\text { flexible; competent; awesome; } \\
\text { appreciate; coffee; food; TV; } \\
\text { leave; quit; cool; friends. }\end{array}$ & $\begin{array}{l}\text { Working relationships: } \\
\text { boss, co-workers and } \\
\text { customers }\end{array}$ & $\begin{array}{l}\text { Explicit reference to positive/negative } \\
\text { relationships with boss, manager, } \\
\text { supervisor; co-workers, customers, } \\
\text { clients: consistent/inconsistent treatment; } \\
\text { flexibility/inflexibility; perks (coffee, food, TV } \\
\text { time); appreciation of effort/lack of } \\
\text { appreciation; socialising; }\end{array}$ & $\begin{array}{l}\text { People } \\
\text { oriented; } \\
\text { intrinsic }\end{array}$ \\
\hline
\end{tabular}




\begin{tabular}{|c|c|c|c|}
\hline & & $\begin{array}{l}\text { competence/incompetence of manager; } \\
\text { awesome boss; praise; recognition. }\end{array}$ & \\
\hline $\begin{array}{l}\text { free; pay; money; discounts; } \\
\text { bonus. }\end{array}$ & Pay & $\begin{array}{l}\text { Tweets that refer to pay: deductions; low } \\
\text { levels of pay; bonuses; perks; pay rises; } \\
\text { discounts; holiday pay. }\end{array}$ & $\begin{array}{l}\text { Money- } \\
\text { oriented; } \\
\text { extrinsic }\end{array}$ \\
\hline $\begin{array}{l}\text { stand; heat; cold; noise; } \\
\text { permanent; temporary; } \\
\text { contract; busy. }\end{array}$ & Working conditions & $\begin{array}{l}\text { Explicit reference to working conditions: } \\
\text { physical effort; sitting/standing all day; } \\
\text { temperature (hot/cold); noise levels; job } \\
\text { security. }\end{array}$ & $\begin{array}{l}\text { Job- } \\
\text { oriented; } \\
\text { extrinsic }\end{array}$ \\
\hline $\begin{array}{l}\text { fun; interesting; cool; } \\
\text { meaningful; boring; } \\
\text { challenging; hard; easy; } \\
\text { difficult. }\end{array}$ & Nature of the job & $\begin{array}{l}\text { Reference to the nature of the work: } \\
\text { Valuable; important to society; } \\
\text { autonomy/lack of autonomy; fun; } \\
\text { interesting. }\end{array}$ & $\begin{array}{l}\text { Job } \\
\text { oriented; } \\
\text { intrinsic }\end{array}$ \\
\hline
\end{tabular}


Table 2. Breakdown of occupations

\begin{tabular}{|l|r|r|}
\hline \multicolumn{1}{|c|}{ Occupation } & No. of Users & \multicolumn{1}{l|}{$\%$} \\
\hline Managers & 20,731 & $16.30 \%$ \\
\hline Professional & 77,620 & $61.04 \%$ \\
\hline Technicians and associate professionals & 19,567 & $15.39 \%$ \\
\hline Clerical support workers & 264 & $0.21 \%$ \\
\hline Service and sales workers & 5,148 & $4.05 \%$ \\
\hline Skilled agricultural, forestry and fishery workers & 22 & $0.02 \%$ s \\
\hline Craft and related trades workers & 1,919 & $1.51 \%$ \\
\hline Plant and machine operators, and assemblers & 711 & $0.56 \%$ \\
\hline Elementary occupations & 219 & $0.17 \%$ \\
\hline Armed forces occupations & 954 & $0.75 \%$ \\
\hline
\end{tabular}


Table 3. Sample tweets in each category

\begin{tabular}{|c|c|c|}
\hline Category & Love my job & Hate my job \\
\hline $\begin{array}{l}\text { Working } \\
\text { hours }\end{array}$ & $\begin{array}{l}\text { *Boss pushed out our } 11 \mathrm{pm} \text { call to } 12 \mathrm{am!} \mathrm{Joy.} \mathrm{I} \\
\text { love my job. I love my job. I love my job. } \\
\text { *I love my job. They're letting us leave early to } \\
\text { go home and watch USA play soccer. }\end{array}$ & $\begin{array}{l}\text { *Boss changed my fucking days. Now l'm working } 5 \\
\text { days a week for two months and can't change it. } \\
\text { *Fuck sake. I hate my job. } \\
\text { * I fvckn hate my job. Just when I'm almost done } \\
\text { getting ready, my stupid job called to tell me I have to } \\
\text { cover tonight's shift! Fckn bs! ???????? }\end{array}$ \\
\hline $\begin{array}{l}\text { Working } \\
\text { relationships } \\
\text { Boss }\end{array}$ & $\begin{array}{l}\text { * may complain about work, but I really do love } \\
\text { my job. I couldn't ask for better managers. }\end{array}$ & \\
\hline
\end{tabular}




\begin{tabular}{|c|c|c|}
\hline Customers & $\begin{array}{l}\text { *So many people hate on their job } \\
\text { but i love my job, it gives me hope and seeing } \\
\text { customers happy is what gives me life. } \\
\text { *I love my job and the people I work with so I } \\
\text { don't mind working overtime. }\end{array}$ & $\begin{array}{l}{ }^{*} \text { Ever since we got new managers I HATE my job } \\
\text { almost a year of working at the same place and I } \\
\text { haven't even gotten a raise from minimum wage? } \\
\text { *i hate my job to begin with. it's just 10x's worse } \\
\text { when i get rude ass customers?? }\end{array}$ \\
\hline Co-workers & & $\begin{array}{l}\text { *Fucking hate my job!! How can so many } \\
\text { incompetent people get employed!!! }\end{array}$ \\
\hline Pay & $\begin{array}{l}\text { *'ve been getting paid the past } 6 \text { hours and all } \\
\text { l've done is sit in my hotel room. Man I love my } \\
\text { job. } \\
\text { *I don't have to work for the rest of the week but } \\
\text { I'm still getting paid for all those days???? }\end{array}$ & $\begin{array}{l}\text { *Why did i agree to work this week who cares if } \mathrm{i} \\
\text { need money, i hate my job } \\
\text { *What a punishment i hate my job but i want money } \\
\text { Ughh i hate my job but i need money soo oh well }\end{array}$ \\
\hline
\end{tabular}




\begin{tabular}{|c|c|c|}
\hline $\begin{array}{l}\text { Working } \\
\text { conditions }\end{array}$ & $\begin{array}{l}\text { *Crazy day at work but I love my job. } \\
\text { *I love my job. Its so easy. Right now i'm being } \\
\text { paid for sitting down, eating Lays Cheesy Garlic } \\
\text { Bread Chips, And Browsing Social Networks. }\end{array}$ & $\begin{array}{l}\text { *Gosh I hate my job when it's too hot. I'm going } \\
\text { home. } \\
\text { *I'm so cold my bones are aching. I'm probably } \\
\text { dying. *Who knows. Who cares. Good night. I hate } \\
\text { my job. } \\
\text { l'm so tired and I truly hate my job. }\end{array}$ \\
\hline $\begin{array}{l}\text { Nature of the } \\
\text { Job }\end{array}$ & $\begin{array}{l}\text { *Tired but fulfilled. I love my job. } \\
\text { *What an awesome days work. I love my job. } \\
\text { *I love my job! Don't know another job. that's so } \\
\text { much fun. }\end{array}$ & $\begin{array}{l}\text { *I hate my job, and I hate that I will be there ALL } \\
\text { DAY. I have no fun at work anymore ?? } \\
\text { *I really hate my job. Not cause it's hard but cuz its } \\
\text { borin as fuck, same shit every damn day! Ó At least u } \\
\text { can wear headphones. }\end{array}$ \\
\hline
\end{tabular}


Table 4. Sample of combined 'love' and 'hate' tweets

\begin{tabular}{|c|c|c|}
\hline Category & Love my job but ... & Hate my job but ... \\
\hline $\begin{array}{l}\text { Working } \\
\text { hours }\end{array}$ & $\begin{array}{l}\text { *Why did I volunteer to work } 7 \text { and a half hours } \\
\text { on Monday ?? I love my job but damn that's a } \\
\text { long shift } \\
\text { *I really love my job but I hate that it takes an } \\
\text { hour to get there each way and so by the time } \\
\text { I'm home l've done a } 11 \text { hour day and am } \\
\text { dead. } \\
\text { *I love my job but it's hard to remember why I } \\
\text { do, on a } 16 \text { hr Monday. }\end{array}$ & $\begin{array}{l}{ }^{\star} \text { I want more hours, but I hate my job. } \\
{ }^{\star} \text { I hate this job so much. But seeing my sweet bosses } \\
\text { face makes me not want to quit. } \\
{ }^{\star} \text { I hate my job but hey it's Friday. I wouldn't wish this } \\
\text { job on my worst enemy. Actually, yes, yes I would. }\end{array}$ \\
\hline $\begin{array}{l}\text { Working } \\
\text { relationships } \\
\text { Boss }\end{array}$ & & \\
\hline
\end{tabular}


${ }^{*}$ l love my job but hate my boss cause she has a rude way of talking to people.

*Anybody in any type of retail business? I love my job but not my boss. I'm a hard worker, quicker learner. I need a new retail job

Customers *These motherf***ers that shop at my job are so lazy and ruthless Imao .. I love my job but I can not stand these people.

*I love my job when I do stock, windows, etc. but helping customers? No.
*I hate my job but the boss telling me not to come is even worse. *I need the money to fly for the PaleyFest!

And then to NY; my latest idea:)

*I hate my job but I love my boss. When I walked in today,she said, "So I assumed you'd need Feb 3rd off \& already put you on PTO that day."

*The only part about my job I hate is dealing with rude customers. Besides that, I absolutely love my job.

\#BestManagementEver

*I seriously hate my job more then I ever thought possible! I have the greatest group of kids but I cant stand my coworkers! 


\begin{tabular}{|c|c|c|}
\hline Co-workers & $\begin{array}{l}\text { *Yeah, I like to talk shit about my co-workers, } \\
\text { but I love my job and I thank god for giving me } \\
\text { the chance to have one. }\end{array}$ & $\begin{array}{l}\text { *I hate my job but I can't quit because I'm too in love } \\
\text { with the people I work with ?????? u gotta luv } \\
\text { everythin abt the job }\end{array}$ \\
\hline Pay & $\begin{array}{l}\text { *I mean I love my job Honestly I do but I need } \\
\text { to get paid more. } \\
\text { *I love my job but some days when I come } \\
\text { home with so many bruises from kids' bites, I } \\
\text { just feel like I don't get paid nearly enough lol } \\
\text { *I love my job but damn can I start getting this } \\
\text { REALLLL money already?! Just a few more } \\
\text { hours!!!!! }\end{array}$ & $\begin{array}{l}\text { *I hate my job but LOVE the money! } \\
\text { *Having money is nice. Hate my job but love my money } \\
\text { lol. } \\
\text { *I hate my job but love that paycheck. } \\
\text { *Honestly hate my job but l've gotta make money. }\end{array}$ \\
\hline $\begin{array}{l}\text { Working } \\
\text { conditions }\end{array}$ & $\begin{array}{l}\text { *I love my job but sometimes you just sit and } \\
\text { cry then take a breath and go on. } \\
{ }^{*} 97 \text { bucks later I'm finally home from work. I } \\
\text { love my job but I'm tired. }\end{array}$ & $\begin{array}{l}{ }^{*} \text { Greatest love/hate relationship with my job bc I looove } \\
\text { my coworkers, but I hate the fact that I'm always } \\
\text { exhausted. }\end{array}$ \\
\hline
\end{tabular}




\begin{tabular}{|l|l|l}
\hline $\begin{array}{l}\text { *Nothing will ever compare to a long hot } \\
\text { shower after a long stressful day at work. } \\
\text { absolutely love my job but today was rough! }\end{array}$ & else work \\
& awesome about sitting on my ass watching someone \\
\hline
\end{tabular}

